Journal of Language \& Translation 10-2

September 2009, 87-128

\title{
Grice in Translation: The Case of Hrabal ${ }^{*}$
}

\author{
Miriam Margala \\ University of Rochester
}

\begin{abstract}
This paper analyzes Gricean conversational principles and their relevance to translation. The central claim is that the Gricean framework illuminates some of the most frustrating challenges in literary translation, and is especially useful with regard to translating finely nuanced constructions and semantically richly layered and complex expressions that constitute essential elements of the narrative. Specific examples of English translations of literary works of Bohumil Hrabal, a Czech author known for his highly idiosyncratic style and innovative expressive methods, are analyzed in accordance with Gricean principles. Recognition of implicatures in the text is shown to be absolutely essential for an effective translation. The detailed examination undertaken in the paper highlights both the great challenge to translators presented by the underlying complexity and semantic richness of Hrabal's writing, and the possibility of gleaning more of the nuances of the author's intention through understanding, in light of Grice's communicative principles, how he achieves his ends. A comparison of translations also demonstrates that failing to recognize and identify implicatures
\end{abstract}

\footnotetext{
* My thanks go to my advisors, Professors Greg Carlson and Christine Gunlogson of the Department of Linguistics at the University of Rochester for their insights, support and suggestions, which helped in shaping this paper.
} 
in the original may lead to ineffective, one-dimensional translations that lack the richness and expressiveness of the source text.

Keywords: cultural translation, literary translation, translation problems, effective translation, Gricean conversational principles, implicatures, Cooperative Principle, translation of implicatures, authorial intention, semantic nuances, Czech literature, Bohumil Hrabal.

\section{Introduction}

In literary translation, cultural understanding is of utmost importance in the process of translation. Culturally charged constructions and semantically nuanced expressions present a great challenge to every translator. Here, Gricean conversational principles offer a useful framework within which the translator can analyze culturally charged expressions and implicatures and arrive at a translation which retains the cultural import of the source text. Specifically, I will analyze examples of implicatures from literary works of Bohumil Hrabal and their English translations, applying Gricean conversational principles and demonstrating how critical it is to recognize all implicatures in the text in order to arrive at an effective translation. The choice of Hrabal, a Czech author, is intentional, as his literary works are well known for his highly idiosyncratic style and innovative expressive methods. The underlying complexity and semantic richness of Hrabal's writings present a great challenge to translators who need to be aware of the author's intentions, inasmuch as possible, with regard to the reading and understanding of the text. Failing to read and understand Hrabal's texts within their complexity, and consequently, failing to recognize and identify implicatures in Hrabal's texts may lead to ineffective, one-dimensional translations that do not reflect the richness and expressiveness of the original. 


\section{Translation Studies and Grice}

Before analyzing concrete examples from Hrabal's works, I will first outline the current situation in translation studies vis-à-vis Grice. There are translation studies scholars who have adopted the Gricean paradigm in a theoretical, general fashion, applying it to address cross-cultural, textual and genre-related issues rather than to issues explicitly related to implicatures ${ }^{1}$. The analysis and discussion of the viewpoints of these scholars will show that their application of Grice is not completely congruous with the aim and scope of Grice's paradigm, thereby not offering practical help in defining and elucidating challenges of conveying implicatures in translation. Then, by analyzing literary examples, I will proceed to demonstrate that there are lines of inquiry into translation problems where Grice's paradigm can be effectively applied to analyze and clarify these problems. The analysis will also exemplify the ways in which the paradigm offers practical tools, concrete language and terminology that facilitate analyses of translated texts and detailed discussions of particular issues and challenges in translating literary texts. With each example, I will first analyze the original expression or construction and explain the implicatures present within the particular context. I will then turn to the existing English translation and carry out a comparative analysis of the original and its translation. The aim and focus is to discuss, analyze and compare texts, all conducted within the Gricean framework, rather than to offer new solutions. ${ }^{2}$

\footnotetext{
${ }^{1}$ See, for example, works by Baker, Venuti and Robinson in the Bibliography section.

${ }^{2}$ In order to preclude possible misunderstandings regarding the terminology usage, I have to acknowledge that due to the complex nature of literary writing and crafted language, some of the literary examples analyzed in this paper may not fall easily and clearly into the category of conversational implicatures as specifically understood by pragmaticists. Grice originally coined and defined implicature in a much narrower sense than it is used in literature. Even though the concept is extended when used in literature and literary analysis, the overall argument and discussion are carried out within the Gricean spirit. The goal is to demonstrate
} 
In addition, it is important to emphasize that my goal is not to analyze or reanalyze Grice's paradigm but to apply it within its original frame, as proposed by the author himself. I will therefore now reiterate some of the points that Grice makes rather clear and to which I will adhere throughout this discussion. Simply put, Grice attempts to formulate a general conversational principle that would illuminate the process of communicating and arriving at the meaning of utterances, which often lies beyond of what is actually being said. First, Grice offers a general description of communication and its general principle:

The following may provide a first approximation to a general principle. Our talk exchanges do not normally consist of a succession of disconnected remarks, and would not be rational if they did. They are, characteristically, to some degree at least, cooperative efforts; and each participant recognizes in them, to some extent, a common purpose or set of purposes, or at least a mutually accepted direction.

Following this, the speaker, by participating in a conversation, agrees to follow this 'mutually accepted direction' and to be cooperative by accepting certain principles guiding conversation. This cooperative aspect of communication is formulated in Grice's cooperative principle:

Make your conversational contribution such as is required, at the stage at which it occurs, by the accepted purpose or

clearly the advantages of Grice's framework and the possibilities and opportunities for the future research in translation that this framework offers. Whenever possible, the analysis is clear and transparent with regard to the application of the Cooperative Principle and the Gricean paradigm. 
direction of the talk exchange in which you are engaged.

Grice further elaborates this principle by proposing four maxims, which when followed, yield cooperative exchange of information. The first is the maxim of relation, i.e. be relevant when you speak, the second is the maxim of quantity, i.e. be as informative as required. Then, the third is the maxim of quality, i.e. say only what you believe to be true and finally, the fourth maxim - the maxim of manner, i.e. be perspicuous, orderly, brief and avoid obscurity and ambiguity. By formulating this framework, Grice attempts to answer the question of how the speakers arrive at meanings that lie beyond of what is overtly said in conversation. More specifically, Grice asserts that participants in any conversation assume that all speakers are cooperative. Based on this assumption, they try to make sense of what is said. As Grice quite eloquently explains in The Philosophy of Language, there are situations when speakers do not say overtly what they really mean, rather, assuming that all the participants know that the speaker is being cooperative, they let the listener work out the covert meaning(s). In other words, the listener is expected to recognize a conversational implicature.

There are also situations where overt flouting of maxims, as opposed to cooperation, gives rise to conversational implicatures; the famous example of a (non)recommendation letter comes to mind (Grice 1989: 33). ${ }^{3}$ It could be argued that the Cooperative Principle and the maxims are not specific enough or too vague; however, what Grice is attempting to achieve is simple and clear - to address issues relating to communication between speakers and to find a general principle that seems to be followed. There is a feature of simple

\footnotetext{
${ }^{3}$ Grice gives the following example of flouting of the first maxim of Quantity: "A is writing a testimonial about a pupil who is a candidate for a philosophy job, and his letter reads as follows: "Dear Sir, Mr. X's command of English is excellent, and his attendance at tutorials has been regular" (Grice 1989: 33).
} 
practicality and common sense incorporated in the Cooperative Principle; based on his Logic and Conversation, it is safe to assume that Grice does not aspire to address any abstract, theoretical, ethical or ideological inquiries.

\subsection{Grice and Baker}

There are scholars within translation studies who have attempted to apply Grice to more theoretical issues in addition to, or even instead of, more concrete, practical problems related to implicatures, including Baker (1992), Venuti, and to some extent Robinson. In translation studies, it is often theorized that there are two ways in which the Cooperative Principle can be applied to translation (Baker 1998). In a broader, general sense at the "macro-level", the Cooperative Principle of the target language is followed, or exploited as the case may be, when analyzing the original text based on its genre, style, or its message which may or may not be seen as controversial, politically incorrect, ethically ambiguous or provoking within its original environment. This particular line of analysis does not address actual instances of implicatures as they arise in conversation. Rather, it addresses theoretical, ethical and ideological issues related to cross-cultural, social, and political problems in translation and the publication of translations within the framework of Grice's paradigm. In other words, this argument is based on the premise of cross-cultural conversation carried out by means of translation. Thus understood, this extensive and complex type of conversation then necessarily imports complex theoretical, ethical, ideological and political issues, which according to these scholars, can be identified and explained by applying the Gricean paradigm.

In contrast, a micro-level analysis addresses concrete instances of implicatures and contexts in which they arise. Obviously, the translator has to first recognize and then comprehend implicatures in the original. In terms of translating them, the translator needs to 
analyze the context in which implicatures arise and the effect of any given implicature in the source language. Then, s/he proceeds to identify linguistic and pragmatic means that would achieve a similar effect in the target language.

Baker (1992) illustrates the application of the Cooperative Principle on the broader, macro level (the textual level of analysis) with an example of two different academic discourses, German and American. German academic discourse is known for its nonlinearity and digressions when compared to American academic discourse. For example, in Fritz Schutze's Sprache soziologisch gesehen, "there are "not only digressions, but also digressions from digressions. Even within the conclusion, there are digressions"" (cited in Baker 1992: 236). Baker points out that when translating German discourse texts into (American) English, the maxim of Relevance and the maxim Be brief "need to be redefined". She asks whether "this apparent violation of the maxims [can] render a German text partially incoherent if it is not adjusted in translation" (1992: 236, my emphasis). While the question of how to approach this problem in translation is valid and open to a fertile, needed discussion, the assumption of violating the maxims is questionable. Granted, from the point of view of an American scholar it may appear so but for anybody who takes part in German academic discourse, this is the style that is routinely followed; therefore, the maxims are adhered to. Here, the mention of style begs another question - is Baker's example truly relevant to Grice's Cooperative Principle? Grice does not address style or genre as such. In this case, it may be argued that the two distinct discourses are two distinct styles of presentation, and while it may be difficult to understand them at the beginning, scholars, students and academics do get eventually used to them and start writing and presenting according to the style of the community they have become part of. In other words, the problem here is not necessarily that of uncooperativeness and figuring out meanings beyond of what is said. Rather, this is an 
issue of learning to become part of a particular community which follows a certain type of discourse. The aim here is to cooperate within a particular community of people.

\subsection{Grice and Venuti}

Venuti $(1995,1998)$, one of the best known translation scholars, goes even further in applying Grice to translation. His stance on translation is based on his dislike of what he believes to be the global hegemony of English. In The Translator's Invisibility, Venuti provides tables and graphs showing that in 1990, out of all the books published in the United States, only $2.96 \%$ were translations into English (1995: 12). ${ }^{4}$ According to Venuti, this negligible exposure to foreign literature in the United States results in assimilationist translations, i.e. translations which completely "hide" the fact that they are, in fact, translations of literary works originated in a foreign language. To counter this hegemony, Venuti asserts that "good translation is demystifying: it manifests in its own language the foreignness of the foreign text" (Venuti 1998: 11). In his view, the assimilationist approach perpetuates the values and attitudes of the major, dominant language and culture, which, in turn, accentuates the above-mentioned hegemony. While he acknowledges that translation is inherently target-oriented, i.e. by definition, translation is geared towards the audience of the language into which a text is translated, he advocates an ethical stance that "urges that translations be written, read, and evaluated with greater respect for linguistic and cultural differences" (Venuti 1998: 6). His brief linguistics-based discussion of translation is critical of the method within which, as he

\footnotetext{
${ }^{4}$ This trend seems to continue as exemplified by the name of an online resource operated by the University of Rochester Open Letter press, aptly called Three Percent. Open Letter press publishes translations of foreign literary works; Three Percent is dedicated to online discussions about translation related issues (see www.rochester.edu/threepercent).
} 
believes, translation is theorized linguistically:

Translation is theorized on the model of Gricean conversation, in which translation communicates the foreign text by cooperating with the domestic reader according to four 'maxims': 'quantity' of information, 'quality' of truthfulness, 'relevance' or consistency of context, and 'manner' or clarity.

(1998: 21)

While Venuti seems to be critical of this particular vein of linguistic theorizing of translation, he then proceeds to set his own argument under the umbrella of Gricean maxims. Combining his ideology with the theory of Gricean maxims, Venuti concludes that

to redress the global hegemony of English ... to evoke the foreignness of the foreign text, an American literary translator must not be cooperative, but challenging, not simply communicative, but provocative as well. Grice's pacific maxims encourage translation that strengthens current [assimilationist ethics].

(1998: 23)

In terms of a robust discussion within the field, Venuti submits an interesting, complex and challenging moral, ethical and ideological concept of translation; however, the question of whether or not applying Gricean maxims is the most productive way to illuminate his opinion remains.

Again, this is the problem of applying Grice on macro-level. In fact, this example goes beyond the macro-level as analyzed in the German academic discourse example. Here, Grice is applied to support an ethical, ideological stance even though Grice himself never set out to address such themes and issues within his 
framework opting to address much more concrete everyday communication problems. Furthermore, Venuti is in fact reformulating the Cooperative Principle when he states that uncooperativeness implies being challenging and uncommunicativeness leads to being provocative. What Venuti seems to understand by uncooperativeness is different from Grice's explanation of uncooperativeness. Grice does not address the problems of challenging and provocative communication in this rather abstract approach. Instead, he addresses, to put it succinctly, a very concrete issue of how implicatures arise in communication and how listeners work out their meaning. As with Baker, Venuti too is compelled to reformulate Grice's framework. Perhaps a more productive and less confusing argument could be formulated without applying Grice to this particular issue, especially since Grice himself never intended his framework to give account of any moral or ideological view of communication.

\subsection{Grice and Robinson}

Yet another way of adapting Grice is presented in Performative Linguistics by Douglas Robinson (2003). As always, Robinson proposes a very interesting argument that challenges the status quo in the fields related to translation and again, his engaging writing is an excellent invitation for a further discussion about the relationship and connections between the fields of translation studies and linguistics. As the scope of Robinson's book is wide ranging (throughout the book, Robinson presents his ideas with admirable sense for details), I will select and discuss only a few issues, which are closely related to the topic of this paper. The following discussion in no way presents a complete and detailed analysis of Robinson's book.

Extending and further elaborating the original distinction as proposed by J.L. Austin (1962), Robinson starts by positing and defining two opposing camps in linguistics - constative versus 
performative linguistics. Constative linguists are those "interested in stable ("constatic") patterns, structures, rules, ..., language in the null context" (Robinson 2003: 4). Performative linguists, on the other hand, are "interested in actual language use in real-world contexts ... specifically in how humans perform verbal actions and respond to the verbal actions performed by others" (ibid. 4). Grice, then, classifies as a constativist whereas translators, for example, are performativists. Expanding this proposition further, Robinson states that as a constativist, Grice's approach to communication is faulty because Grice bases his theorizing on an assumption that "analytical categories are primary and usage secondary, that the "rules" somehow exist somewhere ... and then somehow get obeyed or broken in actual language use" (2003: 148). However, in Logic and Conversation, Grice devotes a lot of space to what we can observe in communication and, before formulating his paradigm, offers many examples taken from 'real-world contexts'. For example, Grice presents a 'real-world' situation where he describes a communication event between three friends:

Suppose that A and B are talking about a mutual friend, C, who is now working in a bank. A asks $\mathrm{B}$ how $\mathrm{C}$ is getting on in his job, and B replies, Oh quite well, I think; he likes his colleagues, and he hasn't been to prison yet. At this point, A might well inquire what B was implying, what he was suggesting, or even what he meant by saying that $C$ had not yet been to prison.

(Grice 1989: 24)

In fact, his paper is interspersed with examples of communication and similar descriptions of what can happen in terms of interlocutors (mis)understanding a particular utterance. Clearly, Grice first offers his observations and thoughts on actual conversations between people and, based on those, he proceeds to present his framework. I 
would further argue that even though Grice does propose rules and he does make use of analytical categories, this does not automatically warrant his exemplifying a constative linguist. As the following discussion of concrete examples taken from literature will demonstrate, in literary translation, which exemplifies performative linguistics, it is precisely the use of clear, defined language and terminology that facilitates a transparent and illuminative inquiry and dialogue.

Next, as a corollary issue, the question of the universality of Grice's maxims arises ${ }^{5}$. Robinson asserts that while by Grice's followers his maxims are presented as universal, they are, in fact, not universal at all. As he explains,

Language doesn't "possess" a stable ideal essence that can be discovered and formalized by linguists. Language is social behavior [...] the maxims are fundamentally social assumptions governing language use; the reason Grice had such trouble formulating them in any kind of universal ("constative") way was that social assumptions vary from society to society, and indeed from social group to social group.

$(2003: 130)$

What Robinson marks as Grice's 'trouble', may in fact have been deliberate on Grice's part, however inconvenient and exasperating this has proved to be for linguists, especially pragmatists. In Logic and Conversation, where Grice introduces his conversational principle and the four maxims of conversation, there is little evidence to support the 'non-universality' claim. Both his writing and his claims are repeatedly interspersed with expressions warning

\footnotetext{
${ }^{5}$ This issue is also emphasized by other scholars, for example Baker 1992, Venuti 1998; cross-cultural scholars such as Wierzbicka and Goddard use the term 'ethnocentricity' (Wierzbicka 2003 and Goddard 2004).
} 
the reader against making any sweeping generalizations and formulating precise definitions. For example, when Grice demonstrates how the formalist group may see and understand inference, he gives the reader "an outline of a not uncharacteristic formalist position" (1989: 22). He does not offer a conclusive and precise characteristic formalist position, only an outline of a not uncharacteristic one. In other words, he does not submit that there is only one definite position that all formalists assume. Further, before Grice proposes his view on implicatures, he explicitly states that he only wishes to draw attention "to the nature and importance of the conditions governing conversation" (ibid. 24). Oftentimes, the Cooperative Principle and the maxims are theorized as "immutable laws" rather than "conventions" (Pym 2004: 25).

Probably the most revealing and most relevant to the charge of constative nature of the maxims is Grice's first more or less comprehensive description of a general conversational principle:

The following may provide a first approximation to a general principle. Our talk exchanges do not normally consist of a succession of disconnected remarks, and would not be rational if they did. They are, characteristically, to some degree at least, cooperative efforts; and each participant recognizes in them, to some extent, a common purpose or set of purposes, or at least a mutually accepted direction.

(Grice 1989: 26)

This citation is a rather fitting example of how open to interpretation and adjustments Grice's paradigm is. It is broad and unspecified, so much so that whether it is the English conversational routine, or Italian, or Russian, or the conversational routine in Madagascar (where traditionally, interlocutors are not up front with offering information as English speakers are used to, see Keenan 1983), the description as formulated by Grice is open to adjustments that any 
culture and society may deem appropriate. No matter what culture interlocutors belong to, it is only reasonable to expect that each interlocutor will recognize "a common purpose or set of purposes or at least a mutually accepted direction" of a given conversation.

It is true that Grice does not address any cross-cultural issues that may arise in communication; however, it simply was not his aim to do so. With necessary cultural and social adjustments, his approach may be widely applicable. However, arguments presented by Baker, Venuti and Robinson seem to assume that there are different cooperative principles for different languages. Also, some scholars in cultural studies and cross-cultural pragmatics (for example see the works by Wierzbicka and Goddard in the Bibliography section) argue for the existence of specific cooperative principles for different languages. Nevertheless, as discussed, Grice's Cooperative Principle is simply too general to warrant such an argument. Rather then argue for culturally based cooperative principles, it may be simpler to specify that the actual application of maxims may vary from culture to culture. In other words, although the standards of relevance, quantity, quality and manner vary, it is still reasonable to assume that people do generally follow the Cooperative Principle.

In addition, there is one more issue that is pervasive in translation studies vis-à-vis the understanding of the mechanism for conveying meaning as proposed by Grice. Based on Robinson, Baker, Venuti and other translation studies scholars, it seems that there is too much focus on flouting the maxims as the main mechanism to convey meaning. Robinson, for example, asserts that

"implicature" in Grice's definition implies that unstated information is conveyed to an audience that is able to work out what is being said by reference to cultural/linguistic maxims that are being flagrantly flouted. 
In fact, the Routledge Encyclopedia of Translation Studies states Grice's goal as an "attempt to account for where, how and why the smooth ongoingness of interaction is intentionally thwarted" (Baker 1998: 181). This, however, is not a complete picture of Grice's paradigm. Grice defines three types of mechanisms that give rise to conversational implicatures. The first type is a mechanism "in which no maxim is violated, or at least in which it is not clear that any maxim is violated" (Grice 1989: 32), then, there is the second type, "in which a maxim is violated, but its violation is to be explained by the supposition of a clash with another maxim" (ibid. 32) and finally, there is the last, third type, which "involve[s] exploitation, that is, a procedure by which a maxim is flouted for the purpose of getting in a conversational implicature by means of something of the nature of a figure of speech" (ibid. 33). Clearly, flouting is not the main mechanism for "getting in a conversational implicature". Often, it is the mechanism of adhering to the maxims which gives rise to an implicature. The literary examples analyzed in this paper exemplify adherence to the maxims as a mechanism for creating a context where implicatures need to be worked out.

It must be emphasized that Robinson, while positing two opposing camps of linguistics, tries to identify ways in which the two branches can inform each other. Specifically, Robinson admits that "Grice is probably right: the best guarantee that a dialogue will progress toward mutual understanding would probably be a certain cooperative spirit, a certain goodwill (Robinson 2003: 170). Then, however, he specifies where he perceives the fault of constativists:

But of course, outside of the kind of ideal model constative linguists favor, we can never be absolutely sure that a dialogue is progressing in such a spirit, nor even that a perfectly cooperative dialogue (if we could ever point to one) would produce understanding. All we know is that sometimes people do cooperate, and that sometimes cooperative 
dialogues lead to mutual understanding"

(Robinson 2003: 170)

In other words, for Robinson, Grice did not go far enough. Therefore, Robinson expands Grice's original paradigm to the crosscultural realm. For example, he stipulates a metalocutionary implicature which directly performs an action on the speaker producing an utterance that gives rise to an implicature. In Robinson's words, metalocutionary implicature "performs the action of enhancing selfreflexivity, of nudging a speaker toward awareness of his or her own implied meanings" (2003: 150). While this is a very stimulating and engaging proposition for any translation theorist, Grice's original paradigm was simply not designed to deal with specific crosscultural issues, nor with issues regarding the speaker's selfreflexivity regarding his or her own implicatures.

\section{Grice in Translation: The Case of Hrabal}

Obviously, the decision to apply Grice in the above examples rests on the assumptions made by the authors citing Grice and on their understanding of Grice's framework. As the translation studies field needs to base its analyses and arguments in some sort of commonly understood and agreed upon terms (the terminology within the field often proves to be a challenge - terms vary widely in their application and meaning) perhaps Grice's approach seems to many very appealing because it does offer clear terms to use and to define one's opinion. However, the issue of applying Grice effectively remains and the potential to misapply Grice is great, especially since his own analysis of conversational principles is in many ways vague. Still, if Grice's paradigm is understood within its original scope, then the effectiveness and usefulness of Grice can be demonstrated and emphasized when concentrating on actual examples of implicatures 
in literary works, i.e. on the micro-level, rather then on the macrolevel which addresses genres, styles, theoretical and ethical translation issues of which Grice gives no account in his analysis. The implicatures in question may be simpler, relevant in a narrow context within the narrative. They may also be complex, covert, carrying on significance throughout the entire work. The application of Grice is still carried out in the micro-level environment, i.e. Grice is applied to address issues embodied by concrete implicatures.

The following analysis will demonstrate that the micro-level environment is where the effectiveness and relevance of Grice's framework to translation is best illustrated. It proceeds from rather simple, straightforward examples of implicatures in translation to progressively more complicated, complex examples of implicatures which, if not conveyed in translation, may seriously hinder the understanding and the flavor of the entire literary work. Without a doubt, to convey effectively the flavor of the original is one of the most challenging tasks in literary translation. Thus it is essential that the translator be perceptive of the author's expressive style and methods. This is especially so in the case of Hrabal, whose style, as discussed in the introduction, is particularly idiosyncratic and complex, whose choice of every word and expression is highly deliberate.

\subsection{Repetition as Literary Expression: Not a Case of Prolixity}

Before presenting the first example, some general remarks may help to set up the context in order to establish clearly the connection between literary expression as related to this particular example and the Gricean framework. In literature, repetition is often one of the central and deliberate parts of the author's literary expression, whereas in everyday communication people tend to avoid repetitiveness and prolixity. Grice, notably, built this tendency into his Cooperative Principle as one of the maxims. This is reflected in the 
practice of translation, where it has been noted that repetitions often present a problem. Translators tend to "correct" the repetitiveness of the original. Milan Kundera (1986), a famous Czech writer living in Paris, now often writing in French, notes in The Art of the Novel that in

in the Russian text of Anna Karenina the word 'house' occurs eight times in six sentences ... Yet the word 'house' appears only once in the French translation ... and no more than twice in the Czech. ... Where Tolstoy repeatedly writes skazal ('said'), the French translation uses [synonyms].

(1986: 146)

For the translator, the underlying question should always be whether or not the repetitive use of a word or a construction in fact indicates repetitiveness, redundancy and prolixity or whether it is the case of a "positive" repetition ${ }^{6}$. In Gricean terms then, any positive repetition indicates that the author is being cooperative, rather than prolix and redundant, using repetition as a device to give rise to implicatures.

An illustrative example of positive repetition, i.e. observance of the relevance maxim, can be found in Hrabal's Obsluhoval jsem anglického krále (I Served the King of England). This example demonstrates how by applying positive repetition as author's artistic and expressive method various effects can be achieved; also, how these methods bring about a context in which essential implicatures can be generated. The main character is a waiter of very small build - invisible physically and socially. One of his biggest dreams is to become more important, more respected, and taller. He visits his tailor where the main character can see all the inflated figurines (tailor's forms) of very important clients floating near the ceiling of

\footnotetext{
${ }^{6}$ Using this term leads to a question of what a "negative" repetition would be. To put it simply, a "positive" repetition is used as a device carrying further meanings, whereas a "negative" repetition falls under the category of prolixity and, in Gricean terms, uncooperativeness.
} 
the tailor's storehouse. Contemplating this view, the character believes that his tailor

(1) pochopil, že se chci dostat vejš, než jsem ted'ka, pořád vejš, že mi na tom záleží ....

understood-he that I want to get higher, than I am now, always higher, that me on it matters ...

(Hrabal, Obsluhoval jsem anglického krále, 45)

In English, literally, the character believes that his tailor "understood that I want to get higher, than I am now, always higher, and that it matters to me ..." The translator, Paul Wilson, collapses this phrase into "...that I wanted [sic] to be taller [sic], and how important [it] was [sic] for me ..." (Wilson's translation, I Served the King of England, 43). Wilson omits not only the comparison phrase, but also the repetition of (always) higher, which is the point of this analysis. ${ }^{7}$

At this point in the narrative, the reader already knows that the main character wants to get taller and socially higher than he is right now. Here, Hrabal reiterates again the information, stressing the main character's desperation and making sure the reader is reminded of his smallness in every respect. Then, Hrabal proceeds to reiterate this yet again with always higher not just as a stylistic device, but also as a device to maximize the effect of the message. In addition, by emphasizing the character's desperation so much, Hrabal also covertly reminds the reader of the character's strong resolve to better his situation. Thus, Hrabal's tactic gives rise to the implicature of the sense of desperation, urgency and resolve. The translator makes an arbitrary decision to omit this part thereby not providing the target reader with the essential context. To complicate the matters even more, the term in question, vejš (higher, taller), presents semantically

\footnotetext{
${ }^{7}$ As is apparent, there are more problems with Wilson's translation.
} 
and formally a great challenge to the translator. This Czech adverb is semantically very rich. It imports to the text three relevant connotations: spatial, the character wants to see his inflated figurine fly high; social, the character wants to climb up socially; and physical, the character wants to be taller. Native speakers are aware of all the various connotations the adverb can semantically import to an utterance and Hrabal, by repeating the adverb, emphasizes and reminds the reader of the richness of the adverb and the need to retrieve its nuances, especially within the context of the narrative. Even though the aim of this paper is not to offer the most effective translation solution to each analyzed problem; at this point, a short examination of the possible English translations furthers the main point of the paper - stressing the usefulness of Grice's conversational framework and its potential to illuminate and to offer practical tools to grapple with various translation problems that have been mainly discussed in highly theoretical terms.

The translator chooses to translate the original word as tall, thus obliterating the essential semantic richness of the Czech adverb. While the English high has the spatial and social connotations, it does not imply tallness. Neither captures the polysemy of the original, although high would seem to be a better choice; quantitatively, it implies two features of the original three. However, this is an essential part of the narrative, a crucial image in the story and the translation will be effective only if it is able to capture the threefold polysemy of the original which, in turn, generates the context necessary for the implicatures to arise. At this point, it is necessary to negotiate between the features contained in the target language possible choices. Other items to consider could be elevated; still, this adjective is similar to high in that the connotation of actual tallness is absent; or lofty; again, its features are not easily compatible with the original. Here, there is an added connotation of nobility with respect to spiritual or intellectual qualities, which are incongruous with the main character. To complicate the issue further 
yet, the last two possible choices are part of a more sophisticated, or elevated, English vocabulary. Since the main character is a simple man, using colloquial Czech, a more pedestrian choice would be more effective. In fact, in this particular case, the main character uses a common colloquialism. Instead of the correct form výs, the character uses the colloquial form vejš, i.e. the original vowel undergoes a vowel shift $/ \mathrm{i} / \rightarrow / \mathrm{ej} /$.

Taking all the above pertinent facts and data into account, the translator certainly does have to think carefully how to approach this problem. This example illustrates very well how the linguistic incompatibility between the source and the target languages can become an obstacle to producing an effective translation. At this point, the translator has to make an arbitrary choice as to which features of the original expression will have to be sacrificed and which will be kept. In this case, the translator offers a translation that is impoverished in many ways. In my view, the most fundamental feature of the text in question is its threefold polysemy emphasized by repetition. If this can be effectively reflected in the English translation, then the target reader will have access to the context necessary for grasping the nuances of the text. Moreover, I believe the target language choices should be commonplace. Therefore, an effective translation should contain both English adjectives, taller and higher, in order to maintain the important polysemy of the original. Keeping in mind Hrabal's repetitiveness, extremely relevant in this case, the repetition must be also maintained in the translation. Here, there may be two choices either the translator decides to repeat the entire sequence taller and higher, ... ever taller and higher or, if the translator perceives the repeated phrase structurally and rhythmically as obtuse s/he may opt for taller and higher, ... , ever higher instead. Personally, I would opt for the latter as, in my opinion, the phrase in its entirety clearly reflects the threefold original polysemy and, rhythmically speaking, maintains better Hrabal's own rhythm, which is an essential part of 
his expressive method as well. Having said that, I do appreciate the fact that the longer phrase may emphasize the rich semantics of the original even further. Either way, this translation creates the context necessary for generating the crucial implicatures much more effectively than Wilson's translation; in fact, Wilson's translation omits this entire matter altogether.

\subsection{Omission of Implicatures in Translation: Considering Relevance}

In addition to contributing semantic richness in literary texts, conversational implicatures can often carry an added function. Not only do they imply information beyond that conveyed by the linguistic form, but they may also emphasize an underlying theme or dimension of the entire narrative. In a particularly idiosyncratic novel by Hrabal, Dancing Lessons for the Advanced in Age (Tanečni hodiny pro starši a pokročilé), the author tells the entire story in one sentence. Sexuality and eroticism are both important underlying themes of the story. The author emphasizes this by using, and often repeating, any words implying or at least hinting at anything sexual. One of the stories the main characters narrates is about a priest and the bad luck he has had with his chaplains one of whom

(2) ...přestoupil do československý církve a oženil se. converted-he to the Czechoslovak Church and got married.

(Hrabal, Tanečni hodiny pro starši a pokročilé, 10)

The translator of the novel, however, decided to manipulate the text and translated it as another converted to the Czechoslovak Church simply ignoring the got married part. (Heim, trans., Dancing Lessons for the Advanced in Age, 2). Apart from the fact that the translator, for reasons difficult to grasp, omits to translate important information, he does not recognize that this message in fact is a 
conversational implicature conveying information beyond its overt, linguistic form. ${ }^{8}$ Even if the translator thinks that the previous context in the narrative had made it clear that the priest left the church in order to get married, the translator should be alert enough to realize that and got married is in the narrative for a reason, apart from the fact that an arbitrary decision of the translator to simply omit any part of the original is always highly questionable.

Indeed, an observant reader with the background knowledge about this particular denomination allowing its priests to be married, may be somewhat taken aback by the got married part of the message as it thematically may seem additive. However, a close look at the text reveals that Hrabal is not flouting the maxim of quantity or relevance, he is not being overtly redundant; on the contrary, Hrabal is observing both and thereby creating a context conducive for an implicature to arise. By providing the information about the chaplain getting married right after converting to the Czechoslovak church, Hrabal is covertly informing the reader that the denomination from which the chaplain converted requires their members to be celibate whereas the Czechoslovak Church allows their members to marry. Moreover, beyond this implied "factual" information, there is yet another important implicature. The character - the chaplain - is, obviously, unable to observe the vow of chastity anymore and readily switches to a denomination where he does not need to abstain from sex. Within the narrative, this is an important underlying dimension regarding this particular character's moral ambiguities, especially as they relate to his sexual behaviour. That simple statement collapsing the chaplain's life-changing event into converting ... and getting married only emphasizes the

\footnotetext{
${ }^{8}$ Even though not presenting a problem vis-à-vis translating, it is important to note here that and itself is an implicature. In this particular case, it is implicated that the course of the two events (the priest's converting and then marrying) is consequential, i.e. the priest converted to a different denomination and as a consequence, he was able to get married.
} 
character's readiness to undertake such serious and fundamental changes in his life in order to get what he desires. Further connecting this particular implicature within the overall general context of the narrative, an alert reader may recognize that Hrabal is also hinting at the fact that denominations requiring celibacy may be having problems with retaining priests.

As already mentioned, even the source reader (i.e. the reader of the original speaking the original language, belonging to the original culture) may not be fully aware of the differences among various denominations; not to translate the phrase [and] he got married will only result in that much less understanding of the developing narrative on the target reader's end (i.e. the reader of the translation, speaking the language of the translation). Specifically, the failure to translate this particular text leaves the sexual and erotic dimension of the narrative obscured even though this same underlying sexual theme may actually facilitate the recognition of the implicature by the target reader. Arguably, as mentioned in the analysis, there may even be a broader implicature regarding the more social aspects of religion, its stance towards sexuality and the resulting consequences. Whether or not the social aspects could be easily retrieved within the Gricean framework, this particular analysis demonstrates how the more immediate and fundamental theme of sexuality and eroticism can be worked out within the framework.

\subsection{Context and Implicatures: Lost in Translation?}

Turning to more complex issues, the following examples exemplify further the ways in which Grice's conversational framework facilitates a discourse where precise language can be used in theorizing, exposing and analyzing problems in translation and where these problems can be clearly identified. In literary translation, there are oftentimes cases where it is truly difficult to find any rational explanation that would offer answers as to the translator's 
arbitrary changes $\mathrm{s} /$ he makes in the process of translating. This is so especially in cases where a simple, near-literal translation is possible and effective; yet, the translator chooses to make structural and semantic changes. In the case of the following structure, the translator may have not been alert to one of its very fine dimensions; however, as will become apparent, the structure in question gives rise to an essential implicature in the narrative.

Returning to I Served the King of England, the second chapter begins:

(3) Dávejte pozor, co vám ted'ka řeknu.

Pay attention what to you now say-I.

Koupil jsem si vulkánový nový kufr a do toho kufru jsem složil nový frak,

Bought-I myself vulcanite new suitcase and into that suitcase put-I new tuxedo,

ten, který mi ušil ten krejčí z Pardubic na moji figurínu, that, which for me made that tailor from Pardubice on my figurine,

sám jsem si byl pro ten frak a zástupce firmy opravdu nelhal. myself was-I for that tuxedo and representative of firm really did not lie.

(Bohumil Hrabal, Obsluhoval jsem anglického krále, 45)

The translator decided to translate this part as follows:

(4) I bought a new vulcanite suitcase and into the suitcase I folded away the new tuxedo made to measure for me by the tailor from Pardubice. The salesman had certainly been telling the truth.

(Hrabal 1989: 43, trans. Paul Wilson) 


\section{Grice in Translation: The Case of Hrabal}

In the original, the last sentence is a critical conversational implicature in this short text. Before the reader reads this text, $\mathrm{s} / \mathrm{he}$ has already learned that the character went to meet the tailor; however, by the time the reader gets to this part of the narrative, this information is not easily retrievable. At this point, the reader, assuming the narrator is being cooperative, starts searching for the relevancy of the utterance. Once the reader does retrieve the information about the character having met the tailor, then s/he can complete the entire message of the utterance. From what the character had heard when he first met the tailor, he now concludes that indeed, the tailor did not lie when they first spoke. In other words, by suddenly mentioning the tailor's not lying, the narrator expects the reader to connect the dots by retrieving the relevant information and situating it within this particular point in the chronology of the narrative.

This is, however, only one dimension of the implicature. The other has to do with the actual semantic form of the utterance. In the original, the tailor did not lie. Nevertheless, the translator chose to change the perspective. In his translation, the tailor had certainly been telling the truth. Semantically, the translation is much stronger than the original expression. It is very affirmative (even expanding the translation by adding certainly), implying that the tailor told all of the truth. The original, in contrast, is more ambivalent, suggesting the possibility that, in the past, the tailor may have lied. Arguably, the original casts some doubt on the tailor's character, which is lost in the translation. To translate the original near literally as the tailor did not lie is more effective, generating a context in which the perspective of the utterance is not changed, thereby giving rise to an implicature that is much closer to the original one and does not bring into the narrative any additional nuances and layers of meaning. Furthermore, within the overall context of the novel, keeping the original's perspective is essential to maintaining the tone of the work where pretentiousness, lying and deceit are the chief characteristics of most of the characters. 


\subsection{Fusing the Conventional and the Conversational Imp- licature: (Im)Possible to Translate?}

So far, the above analyses addressed conversational implicatures as outlined by Grice and the alertness it takes to recognize them. Even though Grice does not specifically deal with conventional implicatures or idiomatic expressions, every translator, without a doubt, realizes that to recognize idiomatic expressions is a basic skill s/he has to have; in the recognition realm, this should not present a problem, although translating idioms often becomes a very complex issue. It's raining cats and dogs; by and large, hit the nail on the head, tempest in a teapot - any translator has to be able to immediately recognize these expressions and, based on the context, the translator should be able to find appropriate linguistic and pragmatic means to convey the original idiom in the target language. Since idioms are often culturally expressive and dependent, to find the most effective translation presents a challenge - but this one is quite different from the challenges which conversational implicatures bring into the process. In the following example, Hrabal manages to fuse these two general types of challenges into a case of 'special' implicature in such a smooth and covert manner, that indeed only a very alert reader, perfectly fluent in Czech and highly conversant in Hrabal's style and method can fully appreciate this special instance of implicature. In this particular case, it is the device as such rather than the actual phrase that gives rise to a conversational implicature.

In Hrabal's story Automat Svět, translated by Jeanne W. Nemcova (1967) as The World Cafeteria, a female character invites a male character to sleep with her. Obviously, the story's theme has strong sexual undertones. The male character rejects the woman's offer saying, as translated by Nemcova, you are not my type (Nemcova 1967: 146). This expression - mild, certainly dull for Hrabal, and not particularly rich semantically, can be literally translated into Czech as nejste můj typ. While it is a widely used expression, in 
the original, Hrabal uses a richer, more interesting expression nejste mý gusto (Hrabal, Pábitelé, 199). Literally, it means you are not my gusto. Besides the meaning 'taste', the word gusto, just as in English, carries additional meanings. It also means zest, enthusiastic joy, enjoyment, pleasure. This is the key meaning layer in the context of the story - it reflects its strong sexual and erotic underlying theme.

While there is semantically some overlap of 'gusto' with 'taste', the translator did not do justice to the richness and complexity of the original. Furthermore, and much more importantly, the translator did not recognize that Hrabal, by using this particular expression with its particular semantic structure, is saying much more beyond what the reader can see. First of all, and this should have become apparent to the translator, Hrabal is not using either of the usual idioms "byt podle gusta nékoho (to be fully according to the taste, or gusto, of somebody) or mit dobré gusto (have a good taste)", (Slovnik české frazeologie a idiomatiky, 202). Instead, Hrabal is combining and collapsing the two into an expression that sounds slightly odd to the native speaker; it is marked even though, at least in my case, it took me some time to figure out why it sounds marked. Hrabal uses the phrase very smoothly, it looks inconspicuous; the two unmarked phrases above are so widely used, that this one coined by Hrabal can easily escape undetected. But once it is detected, the implicature can finally play its part. As mentioned already, the expression seems to be slightly odd, out of place, just as the woman's invitation for sex seems slightly out of place, especially in the time of Hrabal's writing the story (ca. 1964). Emphasizing the sexual theme, almost as if to make sure that all the nuances of the word "gusto" are present in his own expression, Hrabal collapses the two expressions into one, which results in an expression that is semantically very dense. Thus, Hrabal cleverly sidesteps having to choose one over the other. Instead, he decides to manipulate the language as he sees fit, all the while showcasing the elegance and eloquence of his style and generating a context rich in implicatures. 


\subsection{Generating New Implicatures in Translation}

All of the analyses so far studied the effects of not detecting, omitting, or not conveying effectively an expression or a literary device that gives rise to implicatures. In the translated text, an essential aspect of the narrative is thus obliterated and the target reader is unable to retrieve all the nuances and implicatures critical to full understanding of the story, its characters and its main thought. In literature, there are also examples of the opposite situation, where the translation generates a context in which implicatures may arise even though in the original, no such context is present.

In Hrabal's story translated by Michael H. Heim as Palaverers, all the characters have very difficult lives. They all hold menial jobs, make little money, live in a terribly polluted part of the country; still, Hrabal depicts them as people who despite their circumstances live in dignity. In particular, there is a female character whose physical appearance is less than appealing; yet, Hrabal's use of language and rhetorical devices makes clear that this woman is a dignified, happy, optimistic, gregarious and very hospitable woman. At one point in the narrative, Hrabal writes that this woman

(5) těžce vylezla na stoličku

heavily got up-she on chair

(Hrabal, Pábitelé, 185)

In this case, a simple translation is possible - with difficulty, the woman got up on a chair. In fact, this translation is near literal, the only cross-linguistic adjustment is the adverbial expression; the Czech adverb těžce ('heavily') translates best as with difficulty. The original phrase simply conveys the fact that the woman, who was overweight and perhaps tired, had some difficulty getting up on a chair. However, the translator chose to translate the phrase as "the woman huffed and puffed her way up to a chair" (This Side of 
Reality: 63). Not only is this translation semantically and structurally additive, it gives rise to ridicule of the female character, which is not implied at all in the original. This ridicule embodies characteristics very demeaning to the woman - it implies she struggled on her way up to the chair as if that were a task as difficult for her as climbing a mountain and, while climbing, she huffed and puffed, implying wheezing, shortness of breath often taken as characteristics of obese or very sick people who have lost their ability to perform basic everyday tasks. The English phrase brings into the story a dimension that is completely incongruous with the character and the point of the story. The woman, while depicted as overweight, is certainly a happy and agile woman, full of life especially as she is later described running around her household taking care of it. The implicature of ridicule is most troubling in this case as the story portrays every character as dignified despite their environment and their physical shortcomings. This particular phrase in the original is not meant to give rise to additional, implied meanings; rather, it simply depicts a woman getting up on a chair with some difficulty.

\subsection{Additional Challenges: Implicatures as a Semantic Network}

Within any narrative, implicatures can also carry on expanded, broader meanings than those narrowly contained within one construction or expression. In certain contexts, implicatures can create an underlying network of a wider meaning, a semantic network, essential to the narrative. Hrabal offers an excellent example of implicatures creating an expansive network of meaning in Pábitelé (Palaverers) (Hrabal 2000: 179-189). In the story, almost all of the male characters work in a cement factory; when they finally retire, they sit all day long on a bench in front of the factory, talking incessantly. Still, they do all they can to elevate and dignify their existence in this depressing, polluted environment. The 
main characters in this story are artists-amateurs who find inspiration and beauty everywhere despite their gloomy lives. Hrabal emphasizes these apparent contradictions with his expressive method of creating a subtext where implicatures fundamental to understanding the nuances of the narrative arise.

By taking advantage of the rich Czech morphology, Hrabal confuses readers by nudging them toward positive feelings at one point but negative right after towards the story's characters. When he introduces the characters of old men sitting in front of the factory, talking incessantly, Hrabal starts with stařici (diminutive, meaning little, dear old men), then continues with dédky (seemingly diminutive due to some morphological similarities with diminutive morphemes but meaning, in fact, dodderers), and last, he characterizes them as dédové (old geezers).

As the translations in the brackets make it clear, the description becomes progressively negative. This, however, is not reflected in Heim's translation because the translator failed to realize the nuances in the original (Heim, from This Side of Reality, 1996). In each case, the various original expressions are translated simply by old men. In the case of starici, one can only guess why this particular diminutive was not translated. This is an example of a typical diminutive morphology (by adding - $\mathbf{i}$ k to the original base word, changed into $-i c i$ in the plural). The expression dédky, however, is a bit more complicated. While it is seemingly another case of a diminutive (by adding -ek to the base of the word, changed into -ky in the plural, another example of Czech diminutive morphology), this is in fact an example of a depreciative use of the word; i.e. the morpheme in this particular case adds a negative coloring to its meaning. It can be retrieved mainly by context though there are other situational and cotextual circumstances as well. The translator did, indeed, understand the general semantic import of the three original words - all meaning men advanced in age. However, Hrabal's careful choice of each is essential to the deeper 
understanding of the story and the method used by the author to express his thoughts. First, what is important is the actual transition from staríci to dédové. When juxtaposed, the change from positive to negative nuance is rather obvious. Hrabal uses another term in the middle - dédky - as a form of 'transitional' word. While not really neutral, its negative nuance is not as strong as in the case of dédové. Then, taking the three stages together, it is the actual move from the positive end to the negative that gives rise to the implicature. The overt contradictions in the lives of these characters (depressing, polluted, boring lives versus their own optimism, seeing beauty and finding inspiration almost anywhere) are also expressed by Hrabal's clever method of using the "false" set of diminutives, which leads to shifts in the reader's own attitudes and feelings towards them. Not only does Hrabal achieve this reader-oriented transition by the clever use of language, he also compels the reader to ponder all the ambiguities embodied in the contradictions of the characters' lives that may be perceived as clearly distinct.

Just in case the reader has missed the implicature, Hrabal depicts another character using the same method, but the network, or the subtext, created in this case becomes progressively more positive. The character is a local man, one of the village artists-amateurs. Hrabal (ibid. 179-189) starts off with mrňavý mužský (puny chap/fellow), then proceeds with mužský (chap/fellow) and finally, mužiček (sweet/dear little man). While mužský is a more or less neutral, very colloquial expression, Hrabal modifies it with an adjective mrňavý - 'puny', which carries a strong negative connotation. Then, Hrabal uses the form mužský - 'fellow', 'chap', alone, without the previous negative adjective. At the end, 'fellow' becomes mužiček - 'sweet, dear little man', a diminutive form carrying a very affectionate connotation. Again, the translator by using simply 'little man' did get the general semantics of the word; however, the subtext created by Hrabal in the original is completely obliterated by the translation. This network gives rise to the implicatures already 
analyzed, albeit from the opposite side of the spectrum. However, when the two subtexts/networks are juxtaposed (this second network of nouns transitions in the opposite way from the first), yet another context is created, giving rise to yet another implicature. Using the morphology of the language in such an ingenious way, creating connected underlying networks of meanings, Hrabal changes the reader's perspective from the positive end of the spectrum to the negative and vice versa in less than one page, thus saying much more than what actually has been said. As demonstrated in the narrative and implied by the expressive language, life as such oscillates between two extreme ends of any aspect of our everyday life and we may seem to think there are always two distinct sides when, in fact, everyday life is filled with ambiguities.

\subsection{Using Redundancy to Generate Implicatures}

Even more complex than the example above, the implicature addressed below is carried throughout the narrative overtly directed toward the reader by the author, thereby setting the overall tone of the work. In addition, this last example also fittingly embodies many of the complexities implicatures bring into the process of translation, many of which have already been discussed within narrower contexts, such as the issue of repetition, the failure to recognize an implicature, and the failure to effectively convey, or even not convey at all, an implicature present in the original. Once again, Hrabal (2000), in his novel Obsluhoval jsem anglického krále (I Served the King of England), conceived an inventive expressive and stylistic device. He envelops each chapter with an instruction for the readers to pay attention to what I am about to tell you now at the beginning and, at the end of each chapter, with will that do? as an apparent invitation for an author-reader discussion: 
(6) Dávejte pozor, co vám ted'ka řeknu.

Pay attention, what to you now say-I.

(Hrabal, Obsluhoval jsem anglického krále, 7, 45, 129, 171)

(7) Stačí vám to? Tím dneska končím.

Suffice for you it? With this today finish-I.

(ibid. 44, 81, 170)

This invitation is deceptive, however, because it is immediately followed by an answer (with this, I'm done for today) evoking the author's authority. To open the discussion, the issue of the repetition of the clauses in each chapter will be addressed first. Here, the underlying question is whether or not Hrabal's repetitive use of the above mentioned clauses in fact indicates repetitiveness, redundancy and prolixity.

First, what is it exactly that Hrabal repeats? The novel consists of five chapters which, taken together, recounts the main character's life. However, each chapter is a self-contained story. Since the opening and closing remarks are indexical in nature, Hrabal cannot be repeating the informational import of the clauses (Pay attention to what I am about to tell you, Will that do? and finally, With this, I'm done for today). Each index refers to a particular story; therefore, though the formulas are the same, the informational import is different as the narrative progresses. It is then the particular device that Hrabal repetitively applies at certain points throughout the novel that carries significance. Second, does this repetitiveness of the device, the formulas, constitute flouting of the maxims of manner and relevance? Is Hrabal being unnecessarily obscure, prolix and does the device become irrelevant due to apparent repetitiveness? A closer look at the method of Hrabal's framing each chapter reveals that he is, in fact, being relevant. He has an agenda and he is conveying his message by observing the maxims of relevance and manner. Framing each chapter with the "same" opening and closing 
remarks, Hrabal, the omniscient author, speaks directly to the readers; in fact, he instructs the readers what to do. This is an ingenious way to draw readers' attention by engaging them in a quasi mini-dialogue with the author; more than that, it is a very authoritative way to speak and, needless to say, unexpected in a literary work. What effects does Hrabal achieves and what is the implicature we, the readers, are supposed to work out? Simply put, Hrabal establishes himself as the author who has the authoritative voice as to how and what is to be told and who repetitively reminds the reader of this fact. The story is told in first person, but by adding the introductory and concluding clauses, Hrabal clearly separates the author from the narrator. In other words, he makes it clear to the readers that he, the author, controls the narrative at all times. Also, he uses the clauses to get the readers' full attention and to make them alert. Further, Hrabal employs the clauses as a clever device to not only separate each chapter from the rest, but also to link each chapter with the previous or the next one, while still keeping each chapter self-contained.

A more detailed analysis reveals further issues and supports the hypothesis that Hrabal is, indeed, being relevant by repeating the formula or the script. Just when the reader is lulled by the apparent repetitiveness, slight but significant differences can be detected in the third and the last chapters. Hrabal uses fine syntactic and some semantic changes to achieve certain effects. The third chapter, the middle of the novel, is important in the development of the main character's life. It is at this point that his life starts to change for the better. Thus, this chapter separates the 'before' and 'after' of the main character's life structurally within the novel and chronologically. At the beginning of the chapter, Hrabal emphasizes his appeal by saying Pay careful attention to what I am about to tell you:

(8) Dávejte dobrej pozor, co vám ted'ka řeknu.

Pay good attention, what to you now say-I.

(ibid. 82) 
This particular semantic addition signals the importance of this chapter. At the end of the chapter, instead of using the interrogative Will that do? With this, I'm done for today, Hrabal uses parataxis That will do, with this I'm done for today thereby adding authority and significance to this particular chapter.

(9) Stačí vám to, tím dneska končím.

Suffice to you it, with this today finish-I.

(ibid. 128)

At this point, he is not asking or inviting the reader to engage in a quasi-dialogue, he is simply telling the readers this is important and this will do for you today. There is yet another possible implicature the device gives rise to at this particular point of the narrative. Could Hrabal, having just finished an important chapter in the book depicting fundamental changes in the main character's life, be saying that at this point he has had enough, is perhaps tired and without asking, he simply informs the reader he, indeed, is done for today. Here, Hrabal's own tiredness echoes the fullness and heaviness of this particular chapter, not only due to the sheer number of events described, but also due to the possible exhaustion, not necessarily draining, perhaps even exciting, that all the sudden, essential changes bring to the main character's everyday life.

Further along, in fact at the end of the last chapter, Hrabal uses the device with yet another subtle semantic change. He, as the omnipresent author, signals strongly to the readers that the final conclusion phrase clearly marks the end of the novel, not just of the chapter. Instead of the usual With this, I'm done for today he says With this, I'm really done. The finality is obvious, especially within the underlying network of the repeated formulas:

(10) Tím ale opravdu končím.

With this but really finish-I.

(ibid. 234) 
The repetition of the device and its seeming redundancy create a necessary context in which implicatures can arise. Without this context, pronouncing Hrabal as the authoritative voice throughout the novel would not be so effectively and elegantly implied. Moreover, the more nuanced, additional implicature pushing readers to realize the fine differences in significance of certain chapters/ points in the narrative can arise precisely because of the repetition of the phrases. The subtle but essential structural and semantic changes become apparent only when understood within the overall expressive tactic of observing the relevance maxim, of demonstrating the relevance of each and every repeated phrase and the network they create. More specifically, it is within this network of the repeated formulas that the departures, however slight, from their exact repetitions become obvious and the positive role of repetition in this narrative becomes explicit and evident. Thus it is imperative that the device be translated especially since it does not present any difficulty structurally or semantically.

What adds further complexity to the issue is the innate ambiguity of literature. In this particular case, even though structurally speaking Hrabal asks readers at the end of each chapter whether or not 'that will do', the underlying problem is that of the authorial intention indeed, does Hrabal really ask the reader will that do and really expect an answer (yes, that will do) to which Hrabal really means to reply with this, I'm done for today? The simple answer is - we do not know with absolute certainty. We know for sure that for an implicature to be worked out, there must be a recognition of the speaker's intent to imply something beyond of what has been said. What if the reader responds no, it will not do? Obviously, Hrabal's answer will not change - with this, he will be done for today no matter what the reader answers. Either way, the author's authority is evoked, Hrabal does not wait for any response from the reader. This demonstrates aptly the complexity of literal translation due to ambiguity, layered meaning and rich nuances always present in 
literature. Yet again, this analysis also clearly exemplifies how Grice and the Cooperative Principle can be applied constructively and can help in defining and illuminating particular issues that need careful attention in the process of translation.

The English translation of this particular text (I Served the King of England, translated by Paul Wilson) omits the sentences altogether. Wilson fails to recognize that the clauses are an essential and critical element of the narrative. By not translating the clauses, not only are the nuance and the style of the original obscured, but also the context and the device necessary for the essential implicature to arise are omitted. Thus, the target reader misses out completely the many layers of meaning embodied in these phrases. Consequently, the reader cannot appreciate the method in which the semantic complexity of the phrases is applied or the context within which the expressive device functions, in this specific case throughout the entire narrative.

\section{Conclusion}

This paper demonstrates that the Gricean paradigm, if adopted within its original, intended aim and scope, provides diagnostic tools of analysis facilitating a transparent examination of the issue of implicatures in literary translation, thereby critically refining the process of identifying, analyzing and ultimately, effectively conveying implicatures in translation. The examination of actual examples of implicatures from literary works of Hrabal and the analysis of their English translations exemplify the concrete ways and methods in which the Gricean framework can inform and contribute in a very tangible, practical way to translation of implicatures. Implicit in this process, as always the case in literary translation, is the problem of the author's intentions. Even though as an academic topic it is a very contentious issue, translators often 
find themselves in a situation where they have to try to understand and discern, as much as possible, the author's intentions in order to translate the text effectively. In future research, adopting the Gricean paradigm specifically to the issue of authorial intentions has a potential to enrich, advance and expand further the discussion of the effectiveness of Grice and his principles in the realm of translation.

\section{References}

Austin, L. 1962. How to do Things with Words. Oxford: Clarendon Press.

Bach, K. The Top 10 Misconceptions about Implicature. Available at URL <www.sfsu.edu/ kbach/TopTen.pdf>

Baker, M. 1992. In Other Words: A Coursebook on Translation. New York: Routledge.

----, (ed.). 1998. Routledge Encyclopedia of Translation Studies. New York: Routledge.

Beaver, D.I. 2001. Presupposition and Assertion in Dynamic Semantics. Stanford, CA: CSLI Publications.

Blum-Kulka, S. et al (eds). 1989. Cross-Cultural Pragmatics: Requests and Apologies. Norwood: Ablex.

Bouton, F. 1999. "Developing Nonnative Speaker Skills in Interpreting Conversational Implicatures in English: Explicit Teaching Can Ease the Process." Culture in Second Language Teaching and Learning. Ed. Eli Hinkel. Cambridge: Cambridge University Press.

Brown, P. \& S. Levinson. 1978. "Universals in Language Usage: Politeness Phenomena." In E. Goody(ed.) Questions and Politeness. New York: Cambridge University Press.

Carson, J.G. 1998. "Cultural Backgrounds: What Should We Know About Multilingual Students?” TESOL Quarterly 32, 735-746.

Carston, R. 2005. "Relevance theory, Grice and the Neo-Griceans: a response to Lawrence Horn's 'Current issues in neo-Gricean 
pragmatics'." Intercultural Pragmatics 2, 303-319.

Chierchia, G. \& S. McConnell-Ginet. 2001. Meaning and Grammar: An Introduction to Semantics. Cambridge: MIT Press.

Cook, M. \& A. Liddicoat. 2002. "The Development of Comprehension in Inter-language Pragmatics." Australian Review of Applied Linguistics 25, 19-39.

Cronin, M. 2003. Translation and Globalization. New York: Routledge.

Cruse, A. 2007. Meaning in Language: An Introduction to Semantics and Pragmatics. New York: Cambridge University Press.

Dodd, C. H. 1977. Perspectives on Cross-Cultural Communication. Dubuque: Kendall/Hunt Publishing Company.

Drazdauskiene, M. 1981. "On Stereotypes in Conversation, Their Meaning and Significance.” In Florian Coulmas (ed), Conversational Routine. New York: Mouton Publishers.

Enfield, N. J. 2000. "The Theory of Cultural Logic: How Individuals Combine Social

Intelligence with Semiotics to Create and Maintain Cultural Meaning." Cultural Dynamics 12, 35-64.

Grice, H. P. 1967/1989. "Logic and Conversation." Studies in the Way of Words. Cambridge: Harvard University Press, 22-40.

Goddard, C. \& A. Wierzbicka. 2004. "Cultural scripts: What are they good for?" Inter-Cultural Pragmatics 1-2, 153-166.

----. Discourse and Culture. 1997. Discourse as Social Interaction. London: SAGE Publ.

Hamblin, L. \& R. Gibbs. 2003. "Processing the Meanings of What Speakers Say and Implicate." Discourse Processes 35, 59-80.

Horn, L. 2005. "Current Issues in Neo-Gricean Pragmatics." Intercultural Pragmatics 2, 191-204.

Horn, L. \& G. Ward, eds. 2004. The Handbook of Pragmatics. Blackwell Publishing.

Hrabal, B. 1989. I Served the King of England. Trans. Paul Wilson. New York: Harcourt Brace Jovanovich. 
----. 2000. Obsluhoval jsem anglického krále. Praha: Mladá fronta.

----. 1993. Pábení. Praha: Pražská imaginace.

----. 2000. Pábitelé. Praha: Mladá fronta.

----. 1996. Palaverers. Trans. M. H. Heim. This Side of Reality. Ed. A. Buchler. New York: Serpent's Tail, 58-67.

----. 2000. Tanečni hodiny pro starši a pokročilé. Praha: Mladá fronta. ---. 1995. Dancing Lessons for the Advanced in Age.

Trans. M. H. Heim. New York: Harcourt Brace Jovanovich.

Hurford, R. \& B. Heasley. 2007. Semantics: A Coursebook. Cambridge: Cambridge University Press.

Kasper, G. 2004. "Speech Acts in (Inter)action: Repeated Questions." Intercultural Pragmatics 1-1, 125-133.

Kecskes, I. 2004. "Editorial: Lexical Merging, Conceptual Blending, and Cultural Crossing." Intercultural Pragmatics 1-1, 1-26.

Keenan, O. 1983. "The Universality of Conversational Implicatures." Variation in the Form and Usage of Language. Ed. R. W.

Fasold. Washington: Georgetown University Press, 234-247.

Kundera, M. 1988. The Art of the Novel. Trans. Linda Asher. New York: Grove Press.

Lucy, A. 1997. "Linguistic Relativity." Annual Review of Anthropology 26, 291-312.

Mey, L. 2004. "Between Culture and Pragmatics: Scylla and Charybdis? The Precarious Condition of Intercultural Pragmatics." Intercultural Pragmatics 1-1, 27-48.

Munday, J. 2001. Introducing Translation Studies. New York: Routledge.

Nemcova, J. W. 1967. Czech and Slovak Short Stories. London: Oxford University Press.

Portner, H. 2005. What is Meaning? Fundamentals of Formal Semantics. Blackwell Publishing.

Pym, A. 2004. "Propositions on Cross-cultural Communication and Translation." Target 16, 1-28.

Saul, M. 2002. "What is Said and Psychological Reality; Grice's 
Project and Relevance Theorists' Criticism." Linguistics \& Philosophy 25, 347-372.

Sperber, D. \& D. Wilson. 1986. Relevance. Cambridge: Harvard University Press.

Strawson, F. 1964. "Intention and Convention in Speech Acts." Philosophical Review 73, 439-460.

Taguchi, N. 2002. "An application of Relevance Theory to the Analysis of L2 Interpretation Processes: The Comprehension of Indirect Replies." IRAL 40, 151-176.

----. 2005. "Comprehending Implied Meaning in English as a Foreign Language." The Modern Language Journal 89, 543-562. Trosborg, A. 1994. Interlanguage Pragmatics: Requests, Complaints, and Apologies. Berlin: Walter de Gruyter.

Venuti, L. 1998. The Scandals of Translation. New York: Routledge. ----, ed. 2000. The Translation Studies Reader. New York: Routledge.

---- 1995. The Translator's Invisibility. New York: Routledge.

Wierzbicka, A. 2003. Cross-Cultural Pragmatics. New York: Mouton de Gruyter.

----. 2005. "Empirical Universals of Language as a Basis for the Study of Other Human Universals and as a Tool for Exploring Cross-Cultural Differences." Ethos 33, 256-291.

----. 2004. "Preface: Bilingual Lives, Bilingual Experience." Journal of Multilingual and Multi-cultural Development 25, 94-104. 